\title{
BMJ Open Maternal and paternal satisfaction in the delivery room: a cross-sectional comparative study
}

\author{
Marie-Noëlle Bélanger-Lévesque, ${ }^{1,2}$ Marilou Pasquier, ${ }^{2}$ Naomé Roy-Matton, ${ }^{3}$ \\ Simon Blouin, ${ }^{2}$ Jean-Charles Pasquier ${ }^{1,2}$
}

To cite: Bélanger-

Lévesque M-N, Pasquier M, Roy-Matton N, et al. Maternal and paternal satisfaction in the delivery room: a crosssectional comparative study. BMJ Open 2014;4:e004013. doi:10.1136/bmjopen-2013004013

- Prepublication history and additional material for this paper is available online. To view these files please visit the journal online (http://dx.doi.org/10.1136/ bmjopen-2013-004013).

Received 12 September 2013 Revised 13 January 2014 Accepted 14 January 2014

CrossMark

\begin{abstract}
${ }^{1}$ Université de Sherbrooke, Sherbrooke, Québec, Canada ${ }^{2}$ Centre de recherche clinique Étienne-Le Bel du Centre hospitalier universitaire de Sherbrooke, CRC-CHUS, Sherbrooke, Québec, Canada ${ }^{3}$ Hôpital du Centre-de-laMauricie, Shawinigan, Québec, Canada
\end{abstract}

Correspondence to Dr Jean-Charles Pasquier; jean-charles.pasquier@ usherbrooke.ca

\section{ABSTRACT}

Objectives: Maternal satisfaction during the birthing process has been well documented, whereas little is known about the fathers' birth experiences. Our objective was to evaluate and compare the birth satisfaction of mothers and fathers.

Design: Comparative cross-sectional study. Setting: Number of participating centres: one level III maternity centre (2813 births in 2011) in Sherbrooke, Quebec, Canada.

Participants: 200 mothers and 200 accompanying fathers/mother's partner recruited 12-24 $\mathrm{h}$ after the birth over a 6-week period.

\section{Primary and secondary outcome measures:}

The Birth Satisfaction Scale (BSS) was used for the mother, and it was adapted to the father's perspective. Paired-samples $t$ tests were used for comparing mothers and fathers for the BSS global and thematic scores. Multiple linear regressions (forward stepwise method) were made to identify predicting factors of mothers' and fathers' satisfaction.

Results: Global satisfaction scores for mothers $(115.5 / 150)$ and fathers $(114.4 / 150)$ were relatively high and similar $(p=0.116)$. The analysis of subthemes showed that more distress during childbirth was reported by mothers $(p<0.001)$, while less support $(p<0.001)$ and care satisfaction $(p<0.001)$ were reported by fathers. The use of epidural anaesthesia during vaginal birth was the sole concordant lower satisfaction predictor. For mothers, other satisfaction predictors were labour length, tearing and type of anaesthesia used in caesarean section. For fathers, lower satisfaction predictors were instrumental delivery, primary caesarean delivery and infant's distress factors after caesarean section.

Conclusions: This study highlights differences in mothers' and fathers' birth satisfaction and in their predictors. It is thus important to take into account the birth experience of each parent and to support parents accordingly by adapting care provision surrounding childbirth. More research on this topic from the prenatal to the postnatal period is suggested, as it might have an impact on parents' satisfaction and on early parenthood experience.

\section{Strengths and limitations of this study}

- First study comparing mothers' and fathers' birth satisfaction using the same validated measuring scale designed specifically for childbirth.

- Over a 6-week period, all parents of newbornsexcluding cases of major malformations and death in vitro-were met to allow good population representation.

- Despite the fact that the modified Birth Satisfaction Scale was the best starting point to evaluate paternal satisfaction, an interesting perspective would be the addition of questions specifically designed to describe specific fathers' experiences and roles.

\section{INTRODUCTION}

Childbirth is an important life event in a parent's life, and as such is a multifaceted experience. The mother's satisfaction during the birthing process is the most frequently reported indicator in the evaluation of the quality of maternity services. ${ }^{1}{ }^{2}$ A positive birth experience is associated with an increased mother-child bond and maternal abilities, and contributes to her sense of accomplishment and self-esteem. ${ }^{3-6}$ In contrast, a negative birth experience can make the mother feel distraught and have a negative impact on her mental health, increasing the risk of postpartum depression and post-traumatic stress disorder. $^{7-9}$

Despite the increase in the fathers' birth attendance, their feelings and experiences have not been extensively studied. The scientific literature reveals that fathers have their own positive feelings regarding birth: pride related to fatherhood or to the baby, and love and gratefulness towards their partner. ${ }^{10}$ Alternatively, they can feel excluded from the birth by partners and/or health professionals, ${ }^{10}$ and report feeling unprepared for the birth and needing more support. ${ }^{11}{ }^{12}$ 
Studies indicate the need to consider the father's birth satisfaction and needs as a future parent, and not solely as the mother's partner. ${ }^{10}{ }^{13}$ For this reason, validated tools to measure paternal satisfaction during birth, as have been developed recently for mothers, ${ }^{14} 15$ would be appropriate.

Very few studies have been conducted on the satisfaction of both parents, ${ }^{16}$ and even fewer have used an identical instrument for measuring satisfaction, ${ }^{17}$ making comparisons difficult to make. Knowledge of the satisfaction of both parents could provide insight for health professionals as to how to evaluate and adjust the care and services offered to parents during hospitalisation. Hence, this study's aim was to evaluate and compare the birth experience satisfaction of mothers and fathers. The secondary aim was to correlate their satisfaction level with sociodemographic and birth medical data.

\section{METHODS}

\section{Study design and population}

This cross-sectional study, which was approved by our institution's Research Ethics Board (09-148), was conducted between 15 May 2012 and 30 June 2012 at the Centre hospitalier universitaire de Sherbrooke (CHUS; Sherbrooke, Canada), which is a level III maternity centre (2813 births in 2011). Parents were recruited postpartum, at least $12 \mathrm{~h}$ after a vaginal birth and $24 \mathrm{~h}$ after a caesarean delivery. Surveys were completed by parents alone and returned in envelopes before the end of hospitalisation. This timing was chosen in order to maximise survey completion-as parents are very busy after returning home-hence improving population representation. Here "mother" is defined as a woman giving birth and "father" as the father of the child or the mother's life partner (male or female), who was present at the birth. Parents had to be able to read and speak French or English. Cases of major infant malformations or death in utero were excluded. Participating parents signed a consent form, which informed them of the voluntary nature of their participation and of the study's aims, procedures and confidentiality of data (anonymous codification). Authorisation to consult the medical report of birth was also requested.

\section{Data collection}

Data were collected through a self-administered survey, which included the Birth Satisfaction Scale (BSS) and sociodemographic questions, and through the electronic form of the medical report of the birth. The BSS is a validated 30-item survey that was developed to evaluate satisfaction across 15 themes. ${ }^{14} 18$ To do so, perceptions are measured using a series of simple statements with five-point Likert scales (almost half of the items are reverse-scored), which results in a maximum total score of 150. For example, "Pain experienced" is addressed in the BSS by two statements: "Giving birth was incredibly painful" and "Labour was not as painful as I imagined".
To adapt the BSS to the father's circumstances, we modified the statements concerning obstetrical interventions, care provision and perceived pain. For example, "Giving birth was incredibly painful" was modified to "Giving birth was incredibly painful for my partner". The survey was translated into French using the appropriate method ${ }^{19}{ }^{20}:$ (1) a translation and back-translation were made separately by two translators; (2) the translations were evaluated by the research committee and (3) a pilot test with parents of newborns $(n=25)$ was conducted to assess the clarity of the questions.

Most independent variables were categorical, except parental age and labour length, which were represented on a continuous scale.

\section{Statistical analysis}

To determine the required sample size, we aimed to detect a $10 \%$ difference in satisfaction between mothers and fathers, based on the literature. ${ }^{17}{ }^{21}$ Using an SD of 60 points, an $\alpha$ of 0.05 and a statistical power of $80 \%$, the minimum number of couples required was 128 . With a monthly average of 240 births at the CHUS and an estimated response rate of $50 \%$, a study period of 45 days was considered sufficient for the study. BSS questionnaires that were less than two-thirds completed were rejected and others were scaled to obtain a total score of 150 .

We used SPSS V.18.0 software for all statistical analyses. The mean and SD were calculated for continuous variables and a percentage was given for categorical ones. Paired-samples $t$ tests were used for comparing mothers and fathers within couples for the BSS global and thematic scores. As for factors predicting mothers' and fathers' satisfaction, vaginal births and caesareans were analysed separately since many medical variables were not shared. First, simple linear regression analyses were performed to identify significant variables $(\mathrm{p}<0.10)$. Then these significant variables were entered as explanatory variables into multiple linear regressions. Owing to the study's exploratory nature, a forward stepwise method was used.

\section{RESULTS}

\section{Characteristics of study participants}

Among 353 eligible births, we received complete data (father and mother) from 200 couples. In terms of parental characteristics (table 1), fathers and mothers were generally similar. Mothers' average age was 28.7 years and fathers', 31.1 years. More mothers than fathers had a university degree and less were working.

As for the delivery characteristics (table 2), $92.5 \%$ of deliveries were at term, and $38.8 \%$ of women were mothers for the first time. Among vaginal births only, $65.8 \%$ were performed under epidural anaesthesia, and $14.5 \%$ of mothers did not receive any anaesthesia. Labour mean length was: (1) first stage, $306 \mathrm{~min}$ (SD 196.5); (2) second stage, $57 \mathrm{~min}$ (SD 64.6); (3) third stage, 11 min (30.5) and (4) for a total mean length of 371 min (SD 223.7) caesareans made up for $21.5 \%$ of 
Table 1 Parental characteristics

\begin{tabular}{|c|c|c|}
\hline Characteristics & $\begin{array}{l}\text { Mothers } \mathrm{N}=200 \\
\text { Prevalence of } \\
\text { characteristics }\end{array}$ & $\begin{array}{l}\text { Fathers } \mathrm{N}=200 \\
\text { Prevalence of } \\
\text { characteristics }\end{array}$ \\
\hline $\begin{array}{l}\text { Age in years, } \\
\text { mean (SD) }\end{array}$ & $28.7(4.67)$ & $31.1(4.84)$ \\
\hline \multicolumn{3}{|c|}{ Education level, n (\%) } \\
\hline Primary & $2(1.0)$ & $7(3.5)$ \\
\hline Secondary & $36(18.1)$ & $45(22.7)$ \\
\hline $\begin{array}{l}\text { Professional } \\
\text { studies diploma }\end{array}$ & $31(15.6)$ & $52(26.3)$ \\
\hline College & $52(26.1)$ & $31(15.7)$ \\
\hline University & 78 (39.2) & $63(31.8)$ \\
\hline \multicolumn{3}{|c|}{ Marital status, n (\%) } \\
\hline Married & $45(22.5)$ & 45 (22.6) \\
\hline $\begin{array}{l}\text { Common-law } \\
\text { spouse }\end{array}$ & $146(73.0)$ & $147(73.9)$ \\
\hline Other & $9(4.5)$ & $7(3.5)$ \\
\hline $\begin{array}{l}\text { Working status, } \\
\mathrm{n}(\%)^{\star}\end{array}$ & $170(85.0)$ & $191(95.5)$ \\
\hline $\begin{array}{l}\text { Birth outside } \\
\text { Canada, n (\%) }\end{array}$ & $16(7.5)$ & $15(7.6)$ \\
\hline
\end{tabular}

births. Among the babies, $4.3 \%$ had a low birth weight (under $2500 \mathrm{~g}$ ) and $12.3 \%$ were admitted to the neonatology unit for different medical reasons not examined here.

\section{Comparison of satisfaction scores between mothers and fathers}

Results of the BSS are reported in table 3. Average satisfaction scores were 115.5 (SD 13.69) and 114.4 (SD 12.84) for mothers and fathers, respectively, indicating no global significant difference $(\mathrm{p}=0.161)$. Subthemes contributing the most to the global score were: (1) for both parents, "Perception of having received sufficient medical care" and "Health of baby"; (2) for mothers only, "Sufficient support" and (3) for fathers only, "Birth environment".

When analysing the differences between the mothers' and fathers' scores, we observed that the mothers considered themselves more prepared $(\mathrm{p}<0.01)$ and more supported $(\mathrm{p}<0.001)$ than the fathers. Mothers also expressed more distress during the birth $(\mathrm{p}<0.001)$. Meanwhile, fathers were less satisfied with the quality of care provision $(p=0.026)$, their baby's health $(p=0.001)$ and the mother's health ("Obstetric intervention", $\mathrm{p}=0.022$; "Obstetric injuries", $\mathrm{p}<0.001)$.

\section{Satisfaction factors for mothers}

Simple linear regression analyses indicated significant factors $(\mathrm{p}<0.10)$ of maternal and paternal birth satisfaction for vaginal and caesarean deliveries separately. As such, many delivery characteristics and one parental demographical characteristic were identified as
Table 2 Delivery characteristics

\begin{tabular}{|c|c|c|}
\hline \multirow[b]{2}{*}{ Characteristics } & \multicolumn{2}{|c|}{$\begin{array}{l}\text { Prevalence of } \\
\text { characteristics }\end{array}$} \\
\hline & $\overline{\mathbf{N}}$ & Per cent \\
\hline \multicolumn{3}{|l|}{ Type of delivery } \\
\hline Spontaneous vaginal delivery & 143 & 71.5 \\
\hline Instrumental delivery & 14 & 7.0 \\
\hline Primary caesarean & 27 & 13.5 \\
\hline Iterative caesarean & 16 & 8.0 \\
\hline Gestational weeks $<37$ weeks & 15 & 7.5 \\
\hline Primiparity & 76 & 38.8 \\
\hline \multicolumn{3}{|l|}{ Anaesthesia } \\
\hline None & 22 & 11.3 \\
\hline General & 3 & 1.5 \\
\hline Epidural & 119 & 62.6 \\
\hline Rachidian & 12 & 10.8 \\
\hline Pudendal block & 17 & 8.8 \\
\hline Local & 19 & 9.8 \\
\hline Episiotomy* & 17 & 11.0 \\
\hline \multicolumn{3}{|l|}{ Tear* } \\
\hline None & 31 & 20.7 \\
\hline Periurethral & 56 & 37.3 \\
\hline Vaginal & 36 & 24.0 \\
\hline Perineal 1st degree & 28 & 18.7 \\
\hline Perineal 2nd degree & 44 & 29.3 \\
\hline Perineal 3rd degree & 9 & 6.0 \\
\hline Uterine exploration* & 10 & 7.3 \\
\hline Spontaneous placenta expulsion* & 148 & 96.7 \\
\hline Blood loss, over $500 \mathrm{~mL}$ & 42 & 22.1 \\
\hline Fetal monitoring anomalies & 40 & 24.1 \\
\hline Infant sex: boy (vs girl) & 100 & 50.3 \\
\hline Birth weight $<2500 \mathrm{~g}$ & 7 & 4.3 \\
\hline Neonatology admission & 24 & 12.3 \\
\hline \multicolumn{3}{|l|}{ Apgar under 7} \\
\hline At $1 \mathrm{~min}$ & 19 & 9.9 \\
\hline At $5 \mathrm{~min}$ & 3 & 1.6 \\
\hline
\end{tabular}

Owing to missing data, the numbers for each variable might not add up to the same total.

*Percentage calculated for vaginal birth only $(n=157)$.

significant (see online supplemental digital content). These significant variables were entered into multiple linear regression analyses, and the results are described in table 4, including the regression weight.

For mothers with vaginal births, eight significant variables were detected by simple linear regression: (1) positive factors being "no anaesthesia" ( $p=0.032)$ and "periurethral tear" ( $p=0.008)$; and (2) negative factors, "instrumental birth" ( $\mathrm{p}=0.003)$, "epidural anaesthesia" $(\mathrm{p}<0.001)$, "labour length" (first stage $\mathrm{p}=0.010$; second stage $\mathrm{p}=0.012$; total $\mathrm{p}=0.003$ ) and "third degree perineal tear" $(p=0.001)$. In the last multiple linear regression model, four significant predictors remained. Epidural anaesthesia and total length of labour were predictors of lower satisfaction. Also, mothers' satisfaction varied significantly with the presence of tears, increasing when they had periurethral tears and decreasing in the case of third-degree perineal tears. This model accounted for $19.4 \%$ of the variance in maternal satisfaction. 
Table 3 Mothers' and fathers' satisfaction, mean difference and significance by paired t test

\begin{tabular}{|c|c|c|c|c|}
\hline & \multicolumn{2}{|c|}{$\begin{array}{l}\text { Mean satisfaction scores } \\
\text { (SD) }\end{array}$} & \multirow[b]{2}{*}{ Mean difference } & \multirow[b]{2}{*}{ p Value } \\
\hline & Mothers & Fathers & & \\
\hline \multicolumn{5}{|l|}{ Quality of care provision } \\
\hline Home assessment & $6.4(2.48)$ & $6.7(2.04)$ & -0.29 & 0.058 \\
\hline Birth environment & $8.8(1.18)$ & $8.7(1.27)$ & 0.15 & 0.185 \\
\hline Sufficient support & $9.4(0.87)$ & $8.5(1.20)$ & 0.84 & 0.000 \\
\hline Relationship with health professionals & $8.2(1.59)$ & $8.2(1.53)$ & 0.02 & 0.888 \\
\hline Subtotal (maximum 40 points) & $32.8(4.42)$ & $32.2(4.07)$ & 0.70 & 0.026 \\
\hline \multicolumn{5}{|l|}{ Parents' personal attributes } \\
\hline Ability to cope during labour & $7.3(1.67)$ & $7.5(1.57)$ & -0.19 & 0.213 \\
\hline Feeling in control & $7.6(1.57)$ & $7.7(1.56)$ & -0.11 & 0.426 \\
\hline Preparation for childbirth & $8.5(1.43)$ & $8.2(1.53)$ & 0.36 & 0.004 \\
\hline Relationship with baby & $8.5(2.10)$ & $8.4(1.38)$ & 0.16 & 0.364 \\
\hline Subtotal (maximum 40 points) & $32.1(4.52)$ & $31.8(3.92)$ & 0.24 & 0.526 \\
\hline \multicolumn{5}{|l|}{ Stress experienced } \\
\hline Distress experienced during labour & $4.8(1.74)$ & $5.7(2.02)$ & -0.87 & 0.000 \\
\hline Obstetric injuries & $7.8(1.77)$ & $7.3(1.88)$ & 0.43 & 0.000 \\
\hline Perception of having received sufficient medical care & $8.9(1.36)$ & $8.8(1.39)$ & 0.13 & 0.205 \\
\hline Receipt of an obstetric intervention & $6.6(2.74)$ & $6.7(2.66)$ & -0.25 & 0.022 \\
\hline Pain experienced & $5.2(2.00)$ & $5.2(2.00)$ & -0.01 & 0.945 \\
\hline Long labour & $7.3(2.31)$ & $7.4(2.16)$ & -0.09 & 0.409 \\
\hline Health of baby & $9.6(0.810)$ & $9.4(0.94)$ & 0.22 & 0.001 \\
\hline Subtotal (maximum 70 points) & $50.1(7.30)$ & $50.5(7.73)$ & -0.66 & 0.097 \\
\hline Total score (maximum 150 points) & $115.5(13.69)$ & $114.4(12.84)$ & 1.09 & 0.161 \\
\hline
\end{tabular}

For caesareans, five significant variables were detected by simple linear regression: (1) positive factor being "rachidian anaesthesia" ( $\mathrm{p}=0.005) ;(2)$ and negative factors, "primary caesarean" $(\mathrm{p}=0.019)$, "primiparity" $(\mathrm{p}<0.001)$, "epidural anaesthesia" $(\mathrm{p}=0.001)$ and "Apgar under 7 at 1 min" ( $p=0.032)$. "Rachidian anaesthesia" was the only significant predictor remaining in the last multiple linear regression model, explaining $17.3 \%$ of the variance in mothers' satisfaction.

\section{Satisfaction factors for fathers}

For fathers, when mothers delivered vaginally, simple linear regression analysis indicated 10 significant explanatory variables: (1) positive factors being "no anaesthesia" $(\mathrm{p}=0.099)$, "pudendal block" $(\mathrm{p}=0.030)$ and (2) negative factors, "fathers' place of birth outside Canada" $(p=0.043)$, “instrumental birth" $(p=0.001)$, "epidural anaesthesia" ( $p=0.013)$, "labour length" (second stage $\mathrm{p}=0.017$; total $\mathrm{p}=0.007)$, "third degree perineal tear" $(\mathrm{p}=0.005)$ "uterine exploration" $(\mathrm{p}=0.036)$ and "blood loss, over $500 \mathrm{~mL}$ " $(\mathrm{p}=0.034)$. After the multiple regression analysis, only use of epidural anaesthesia and instrumental birth remained as significant predictors of lower satisfaction. This model explained $10.3 \%$ of the variance in paternal satisfaction.

When fathers witnessed caesarean deliveries, eight variables were detexted by simple linear regression: (1) positive factor being "rachidian anaesthesia" ( $p=0.003)$; (2) and negative factors, "primary caesarean" ( $p=0.001)$, "primiparity" ( $p=0.014)$, "epidural anaesthesia" $(p=0.002)$, "fetal monitoring anomalies" ( $\mathrm{p}=0.010)$, "neonatology admission"
( $\mathrm{p}=0.002)$, and "Apgar under 7" (at $1 \mathrm{~min} \mathrm{p}=0.045$, at $5 \mathrm{~min} \mathrm{p}=0.025)$. In the last multiple linear regression model, a primary caesarean and an Apgar score under 7 at 5 min were the sole factors retained as significantly decreasing paternal satisfaction. These two variables accounted for $26.9 \%$ of the variance in paternal satisfaction.

\section{DISCUSSION}

This is the first time that results of a study using the BSS are presented, and it is also an innovation to extend its use to include both parents. To our knowledge, the study of Salonen et $a l^{17}$ is the only other study comparing both parents' satisfaction while using the same tool (a section of Parenting Satisfaction Scale). Compared to their study, we also observed that parents' overall scores were high, although in Salonen et al's study, mothers were slightly more satisfied than fathers $(p=0.004$ and lower than 0.001 in both hospitals included in the study). However, the detailed themes of the BBS and the breadth of medical and sociodemographic variables considered as satisfaction predictors allowed us to draw some distinctions between parents. We were thus able to better understand fathers' satisfaction and provide new insight into mothers' satisfaction. Our results also indicated the differentiated roles played by the mother, as a direct actor in the childbirth, and the father, as a direct witness.

\section{Prenatal factors}

We noted that mothers felt significantly more prepared for childbirth, whereas Salonen et $a l^{17}$ identified that 
they felt more afraid, concerned and insecure during pregnancy. These are not necessarily contradictory results: if preparation can generate less insecurity, the greater anxiety felt by mothers could, in part, motivate them to be more prepared. Moreover, studies indicate that fathers often feel unprepared for childbirth. ${ }^{11} 12$ Parity is a predictor of higher maternal satisfaction in previous research: preceding births can offer some preparation for a subsequent one. ${ }^{622}{ }^{23}$ Nevertheless, parity was not shown to have a clear correlation with parenting satisfaction in our study or in Salonen $e t a l$ s study. ${ }^{17}$ Our data suggest that more investigation is needed to determine if fathers with a country of birth different than their child's have a lower birth satisfaction (simple linear regression analysis: $\mathrm{p}=0.043$ ). Our study is the first, to our knowledge, where this has been observed, even if this was not significant in the multiple linear regression analysis. Higher parental age and educational level have been associated with lower maternal satisfaction, ${ }^{24}{ }^{25}$ but were not significant here; this has also been observed elsewhere. ${ }^{1722}$

\section{Childbirth experience}

The use of epidural anaesthesia during vaginal birth is paradoxical with respect to parental satisfaction. Given its effectiveness and security in pain management, as assessed by a Cochrane review, ${ }^{26}$ it is surprising that our sole variable concord between fathers and mothers is the use of epidural anaesthesia as a significant predictor of lower parental satisfaction. This has also been observed elsewhere for mothers. ${ }^{27} 28$ In fact, a comparison between epidural and non-epidural users in a Cochrane review showed heterogeneity in maternal satisfaction. ${ }^{29}$ Moreover, a new study by the Collectif Interassociatif Autour de la NaissancE (CIANE) revealed that the poor congruence between what was planned concerning this intervention and the reality impacts more the maternal satisfaction than its use or not. ${ }^{30}$ As for fathers, studies indicate that this procedure improves their satisfaction as they feel it enhances their ability to support the mother and the couple's ability to relate to each other, hence reducing the fathers' sense of isolation and uselessness. ${ }^{31} 32$ As such, it is hard to explain why with a similar rate of epidural use, a similar sample size and data collection at the same time, we obtained results that are opposite to those of Capogna et $a l .{ }^{32}$ Clearly, more research using the same birth satisfaction measuring tool must be pursued to allow further comparison.

Fathers' satisfaction also decreased with instrumental birth, whereas mothers' satisfaction, surprisingly, did not. Previous studies indicate similar results as complications during labour were linked to fathers' negative experiences, ${ }^{33}$ and instrumental deliveries generated a less positive birth experience for them. ${ }^{34}$ Salonen et $a l^{17}$ also found no significant effect of instrumental births on mothers' satisfaction. From a medical perspective, this might be due to improved pain management, instrumentation and practice, which include more information

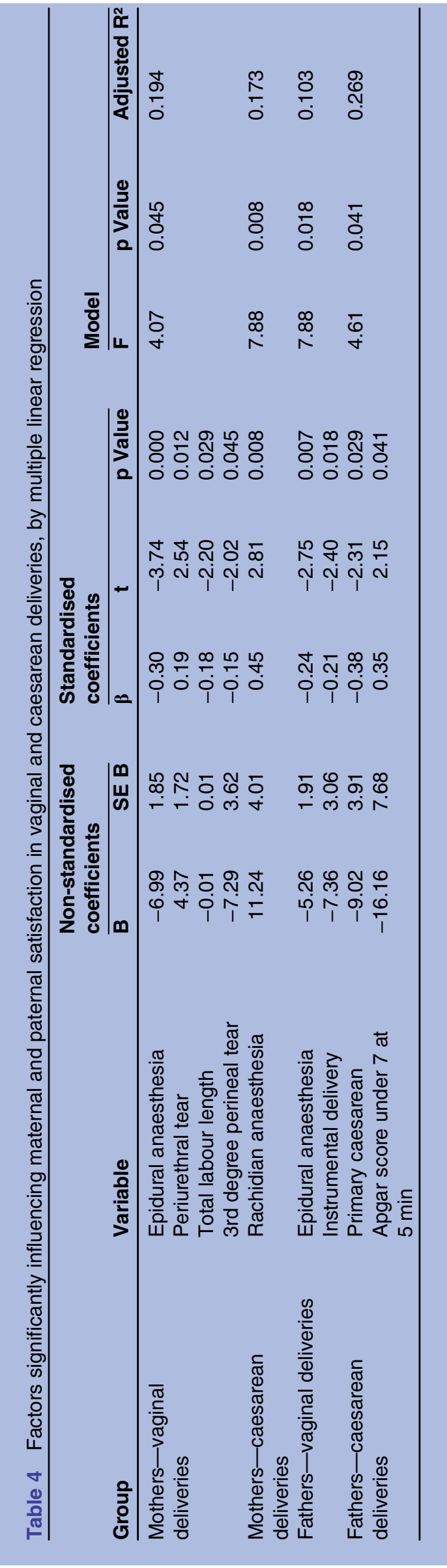


given to the mothers. From the mother's perspective, satisfaction might not change because this takes place during the last moments of the delivery when strain is already at its peak and is rapidly followed by the arrival of the child, concurring with hormonal influx that positively affects the mother's mood. The timing of the evaluation of birth satisfaction might also have been too early as these women might have been in denial of their immediate experience. For example, it has been reported that women who had forceps-assisted births have the poorest health and well-being and ongoing post-traumatic-type symptoms several months after the birth. ${ }^{35}$

As for caesarean deliveries, it appears that it is either the novelty or the unexpectedness that can predict lower parental birth satisfaction. This is true of fathers in this study who witnessed a primary caesarean. Johansson and Hildingsson ${ }^{36}$ found that $46 \%$ of fathers who witnessed emergency caesarean section judged the partner's medical intrapartum care as most deficient, consequently affecting their birth satisfaction. Since rachidian anaesthesia is used mostly in cases of programmed caesarean section, its identification as a predictor of higher maternal satisfaction also mainly indicates that a planned event is preferred to one that is not; similar results have been observed elsewhere. ${ }^{37}$

\section{The mother-father position difference:}

\section{its impact on satisfaction}

The differentiated roles between mothers and fathers in the delivery room are reflected in their discordant results in this study. During childbirth, mothers may directly experience the pain of lengthy labour and tearing, which is significantly associated only with their satisfaction. By contrast, fathers are the direct, and maybe more fully conscious, witness of childbirth, and hence they are more likely to be unsatisfied with what they observe, including "receipt of obstetric interventions", "obstetric injuries" and, as seen elsewhere in the literature, "quality of care provision". ${ }^{36}$ This is also consistent with previous results concerning instrumental deliveries. This might also impact on their early parental role. Fathers' satisfaction was affected by factors related to the health of the baby during a caesarean section birth, a distinction not made by Salonen $e t a l,{ }^{17}$ who found no such significant results. Likewise, we were not able to find similar results elsewhere in the literature that show fathers being less satisfied than mothers for the subtheme "health of baby". This can be explained in part by the timing of the evaluation of birth satisfaction: classical maternal role attainment theory developed by Rubin in the late $60 \mathrm{~s}$-more recently developed as the "becoming a mother" theory by Mercer $^{38}$ - describes motherhood as a process and indicates that if in the immediate postpartum period mothers focused on their own recovery, they rapidly become more focused on their newborn. In fact, our data also indicated a better maternal attachment when the baby was well. When excluding births followed by
Neonatal Intensive Care Unit (NICU) admission-indicating very poor baby health-in further statistical analyses, a new significant difference in parental birth satisfaction appeared: mothers scored on average 0.37 higher than fathers on the theme "Relationship with baby" ( $p=0.035)$, compared to only $0.16 \quad(p=0.364)$ when including NICU admission.

Differences in results could also reflect lower support received by the father during childbirth, as some studies report that fathers said they needed more support. ${ }^{11} 12$ Salonen $e^{~} a l^{17}$ noted that mothers feel more supported during childbirth than fathers: this was also observed in our study, despite similar scores for "relationship with health professionals". As such, distress during childbirth was more strongly expressed by mothers in our study, and lower satisfaction was reported by fathers concerning support and care.

\section{Study limitations}

Even if our response rate was higher than expected, we did not receive completed questionnaires for one-third of the births; those parents might constitute the least satisfied group. Nonetheless, the survey was an exhaustive study conducted 7 days a week in the sole hospital in the region. Moreover, when compared to Quebec's ${ }^{39}$ provincial data, the characteristics of our sample were similar to those of the population in terms of maternal age, parity, prematurity and low-weight babies. A second limitation was the subjective nature of the parents' satisfaction assignment, which could result in the under-reporting of negative aspects (eg, a gratitude bias) or, in contrast, their overestimation (eg, high expectations). A third limitation is possible data contamination if parents consulted each other while completing the survey. Finally, the evaluation of the fathers' satisfaction was based on an adapted version of the BSS, which was originally developed for the evaluation of maternal satisfaction exclusively. However, given the relatively low amount of evidence on fathers' birth experiences, the modified BSS was our best starting point to evaluate paternal experience. Furthermore, these results were more easily comparable to those of mothers. As such, an interesting perspective would be the validation of the BSS for fathers.

\section{Perspectives}

Future research should elaborate on the impact of the different roles played by mothers and fathers, during and immediately after birth, on their satisfaction, as our results suggest. More specifically, some of our results indicate the need for more research on the fathers' experience and specific factors related to their satisfaction in the delivery room. This is especially important as parental birth satisfaction can result in short-term and long-term impacts on their relationship with their infant (ie, perception of baby's well-being, bonding, development, etc) as well as on the mother-father relationship (intimacy, communication, etc) after the birth. 


\section{CONCLUSIONS}

Mothers and fathers presented similar satisfaction in terms of their global scores but differed on some key themes and factors influencing their satisfaction. This study indicates the importance of considering and supporting both parents by adapting care provision during childbirth. Results also suggest the need for more research on this topic, from the prenatal to the postnatal period, as it might have an impact on parents' satisfaction and on early parenthood experience.

Acknowledgements The authors thank the participants for sharing some of their precious time very soon after the birth of their baby.

Contributors M-NB-L, NR-M, SB and J-CP conceptualised the study design and questionnaire. M-NB-L and MP collected and compiled the data. M-NB-L was the main analyst and wrote the first draft of the manuscript. J-CP, SB and MP critically revised the manuscript.

Funding This work was supported by a research grant from Réseau mèreenfant de la Francophonie. MNBL holds a doctoral scholarship from the Fonds québécois de recherche-société et culture.

Competing interests None.

Patient consent Obtained.

Ethics approval Centre Hospitalier Universitaire de Sherbrooke Research Ethics Board (09-148).

Provenance and peer review Not commissioned; externally peer reviewed.

Data sharing statement No additional data are available.

Open Access This is an Open Access article distributed in accordance with the Creative Commons Attribution Non Commercial (CC BY-NC 3.0) license, which permits others to distribute, remix, adapt, build upon this work noncommercially, and license their derivative works on different terms, provided the original work is properly cited and the use is non-commercial. See: http:// creativecommons.org/licenses/by-nc/3.0/

\section{REFERENCES}

1. Bowman MA, Herndon A, Sharp PC, et al. Assessment of the patient-doctor interaction scale for measuring patient satisfaction. Patient Educ Couns 1992;19:75-80.

2. Jackson JL, Chamberlin J, Kroenke K. Predictors of patient satisfaction. Soc Sci Med 2001;52:609-20.

3. Goodman P, Mackey MC, Tavakoli AS. Factors related to childbirth satisfaction. J Adv Nurs 2004;46:212-19.

4. Simkin P. Just another day in a woman's life? Women's long-term perceptions of their first birth experience. part I. Birth 1991;18:203-10.

5. Simkin P. Just another day in a woman's life? part II: nature and consistency of women's long-term memories of their first birth experiences. Birth 1992;19:64-81.

6. Mercer RT, Ferketich SL. Maternal-infant attachment of experienced and inexperienced mothers during infancy. Nurs Res 1994;43:344-51.

7. Beck CT. Post-traumatic stress disorder due to childbirth: the aftermath. Nurs Res 2004;53:216-24.

8. Fenwick J, Gamble J, Mawson J. Women's experiences of caesarean section and vaginal birth after caesarian: a birthrites initiative. Int J Nurs Pract 2003;9:10-17.

9. Righetti-Veltema M, Conne-Perreard E, Bousquet A, et al. Risk factors and predictive signs of postpartum depression. J Affect Disord 1998;49:167-80.

10. Vehviläinen-Julkunen K, Liukkonen A. Fathers' experiences of childbirth. Midwifery 1998;14:10-17.

11. Hallgreen A, Kihlgren M, Forslin L, et al. Swedish fathers involvement in and experiences of childbirth preparation and childbirth. Midwifery 1999;15:6-15.
12. Kopff-Landas A, Moreau A, Séjourné N, et al. Vécu de l'accouchement par le couple primipare: étude qualitative. Gynécologie Obstétrique Fertilité 2008;36:1101-04.

13. Chalmers B, Meyer D. What men say about pregnancy, birth and parenthood. J Psychosom Obstet Gynaecol 1996;17:47-52.

14. Hollins Martin C, Fleming V. The Birth Satisfaction Scale. Int $J$ Health Care Qual Assur 2011;24:124-35.

15. Gungor I, Beji NK. Development and psychometric testing of the scales for measuring maternal satisfaction in normal and caesarean birth. Midwifery 2012;28:348-57.

16. Tingstig C, Gottvall K, Grunewald C, et al. Satisfaction with a modified form of in-hospital birth center care compared with standard maternity care. Birth 2012;39:106-14.

17. Salonen $\mathrm{AH}$, Kaunonen $\mathrm{M}$, Åstedt-Kurki $\mathrm{P}$, et al. Parenting satisfaction during the immediate postpartum period: factors contributing to mothers' and fathers' perceptions. J Clin Nurs 2010;19:1716-28.

18. Hollins Martin CJ, Snowden A, Martin CR. Concurrent analysis: validation of the domains within the Birth Satisfaction Scale (English). J Reprod Infant Psychol 2012;30:247-60.

19. Massoubre C, Lang F, Jaeger B, et al. The translation of questionnaires and of tests: techniques and problems. Can $J$ Psychiatry 2002;47:61-7.

20. Vallerand RJ. Vers une méthodologie de validation trans-culturelle de questionnaires psychologiques: Implications pour la recherche en langue française. Can Psychol/psychologie canadienne 1989;30:662-80.

21. Nichols MR. Paternal perspectives of the childbirth experience. Matern Child Nurs J 1993;21:99-108.

22. Tarkka M-T, Paunonen M, Laippala P. How first-time mothers cope with child care while still in the maternity ward. Int $J$ Nurs Pract 2000;6:97-104

23. Pridham KF, Chang AS. What being the parent of a new baby is like: revision of an instrument. Res Nurs Health 1989;12:323-29.

24. Mercer RT. First-time motherhood: experiences from teens to forties. New York: Springer, 1986.

25. Pridham KF, Lytton D, Chang AS, et al. Early postpartum transition: progress in maternal identity and role attainment. Res Nurs Health 1991;14:21-31.

26. Jones L, Othman M, Dowswell T, et al. Pain management for women in labour: an overview of systematic reviews. Cochrane Database Syst Rev 2012;14;3: CD009234.

27. Koteles J, de Vrijer B, Penava D, et al. Maternal characteristics and satisfaction associated with intrapartum epidural analgesia use in Canadian women. Int J Obstet Anesth 2012;21:317-23.

28. Kannan S, Jamison RN, Datta S. Maternal satisfaction and pain control in women electing natural childbirth. Reg Anesth Pain Med 2001;26:468-72.

29. Anim-Somuah M, Smyth RM, Jones L. Epidural versus non-epidural or no analgesia in labour. Cochrane Database Syst Rev 2011;7(12): CD000331.

30. CIANE. Douleur et accouchement. Enquête sur les accouchements 2013; 5(Avril). http://ciane.net/blog/wp-content/uploads/2013/04/ DossierDouleur.pdf (accessed 17 Apr 2013).

31. Chapman LL. Expectant fathers and labor epidurals. MCN Am J Matern Child Nurs 2000;25:133-8.

32. Capogna G, Camorcia M, Stirparo S. Expectant fathers' experience during labor with or without epidural analgesia. Int J Obstet Anesth 2007;16:110-15.

33. Wikander B, Theorell T. Fathers' experience of childbirth and its relation to crying in his infant. Scand J Caring Sci 1997;11:151-8.

34. Johansson M, Rubertsson C, Radestad I, et al. An emotionally demanding experience for fathers. Sex Reprod Healthc 2012;3:11-20.

35. Rowlands I, Redshaw M. Mode of birth and women's psychological and physical wellbeing in the postnatal period. BMC Pregnancy Childbirth 2012;12:138.

36. Johansson M, Hildingsson I. Intrapartum care could be improved according to Swedish fathers: mode of birth matters for satisfaction. Women Birth 2013;26:195-201.

37. Blomquist JL, Quiroz LH, MacMillan D, et al. Mothers' satisfaction with planned vaginal and planned cesarean birth. Am J Perinato 2011;28:383-8.

38. Mercer RT. Becoming a mother versus maternal role attainment J Nurs Scholars 2004;36:226-32.

39. Québec. Banque des données officielles du Québec. Secondary Banque des données officielles du Québec 2013. http://www.bdso. gouv.qc.ca/ 